\title{
TROCAS GASOSAS E EFICIÊNCIA DO FOTOSSISTEMA II EM PLANTAS ADULTAS DE SEIS ESPÉCIES FLORESTAIS EM FUNÇÃO DO SUPRIMENTO DE ÁGUA NO SOLO ${ }^{1}$
}

David de Holanda Campelo ${ }^{2}$, Claudivan Feitosa Lacerda ${ }^{3}$, João Alencar Sousa ${ }^{4}$, Diva Correia ${ }^{4}$, Antônio Marcos Esmeraldo Bezerra ${ }^{5}$, José Dionis Matos Araújo ${ }^{6}$ e Antônia Leila Rocha Neves ${ }^{2}$

\begin{abstract}
RESUMO - A redução da disponibilidade hídrica causa efeitos sobre a fotossíntese e o desenvolvimento de espécies arbóreas. O objetivo deste trabalho foi avaliar as trocas gasosas e a eficiência fotoquímica do fotossistema II em plantas adultas de gonçalo-alves (Astronium fraxinifolium Schott.), guanandi (Calophyllum brasiliense Cambess.), ipê-amarelo (Handroanthus serratifolius (Vahl.), ipê-rosa (Handroanthus impetiginosa (Mart.) Matos), marupá (Simarouba amara Aubl.) e mogno (Swietenia macrophylla King.) cultivadas em condições de sequeiro e irrigadas, no Perímetro Irrigado do Baixo Acaraú, Ceará. O delineamento experimental adotado foi o de medidas repetidas no tempo, num esquema de parcelas subsubdivididas $(6 \times 2 \times 3)$, sendo a parcela principal composta por seis espécies, a subparcela por dois regimes hídricos (irrigado e sequeiro) e a subsubparcela pelas épocas de avaliação. As análises das trocas gasosas foram realizadas em 22/11/2012 (estação seca), 07/02/ 2013 (data que antecedeu o período chuvoso) e 17/05/2013 (estação chuvosa). As espécies mogno, guanandi e ipê-amarelo mostraram-se mais sensíveis ao déficit hídrico, em comparação com as outras espécies, o que foi evidenciado pelas maiores reduções nas trocas gasosas e na eficiência fotoquímica do fotossistema II. O ipê-rosa, o marupá e o gonçalo-alves mostraram-se mais adaptados às condições de baixa disponibilidade hídrica do solo.
\end{abstract}

Palavras-chave: Estresse hídrico; Plantas lenhosas; Fotossíntese.

\section{LEAF GAS EXCHANGE AND EFFICIENCY OF PHOTOSYSTEM II IN ADULT PLANTS OF SIX FOREST SPECIES AS FUNCTION OF THE WATER SUPPLY IN THE SOIL}

\begin{abstract}
The reduction of water availability causes effects on photosynthesis and the development of tree species. The objective of this study was to evaluate leaf gas exchange and photochemical efficiency of photosystem II in adult plants of gonçalo-alves (Astronium fraxinifolium Schott), guanandi (Calophyllum brasiliense Cambess.), ipê-amarelo (Handroanthus serratifolius (Vahl.), ipê-rosa (Handroanthus impetiginosa (Mart.) Matos.), marupá (Sima roubaamara Aubl.) and mogno (Swietenia macrophylla King.) cultivated in non-irrigated and irrigated conditions, in the Irrigation Perimeter of Baixo Acaraú, Ceará, Brazil. The experimental design was a repeated measures, a scheme of split-plots $(6 \times 2 \times 3)$, with the plot composed by six plant species, the subplot by two water regimes (irrigated and non-irrigated) and the sub-subplots by evaluation dates. The measurements of leaf gas exchange were made in 11/22/2012 (dry season), 02/ 07/2013 (date that preceded the rainy season) and 05/17/2013 (rainy season). The species mogno, guanandi and ipe-amarelo were more sensitive to drought compared to other species, evidenced by greater reductions in leaf gas exchange and photochemical efficiency of photosystem II. The ipê-rosa, marupá and gonçaloalves were more adapted to conditions of low soil water availability.
\end{abstract}

Keywords: Water stress; Woody plants; Photosynthesis.

\footnotetext{
${ }^{1}$ Recebido em 18.12.2014 aceito para publicação em 12.08.2015.

${ }^{2}$ Universidade Federal do Ceará, Programa de Pós-Graduação em Engenharia Agrícola/ Irrigação e Drenagem, Fortaleza, Ceará - Brasil. E-mail: <davidcamppelo@gmail.com>e <leilaneves7@hotmail.com>

${ }^{3}$ Universidade Federal do Ceará, Departamento de Engenharia Agrícola, Fortaleza, Ceará - Brasil. E-mail: <cfeitosa@ufc.br>.

${ }^{4}$ Embrapa Agroindústria Tropical, Fortaleza, Ceará - Brasil. E-mail: <joao.alencar@embrapa.br $>$ e $<$ diva.correia@embrapa.br $>$.

${ }^{5}$ Universidade Federal do Ceará, Departamento de Fitotecnia, Fortaleza, Ceará - Brasil. E-mail: <esmeraldo@ufc.br>.

${ }^{6}$ Universidade Federal do Ceará, Programa de Pós-Graduação em Agronomia/ Fitotecnia, Fortaleza, Ceará - Brasil. E-mail:

<dionisufc@gmail.com>.
}

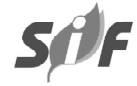




\section{INTRODUÇ̃̃O}

Atualmente o setor de produtos florestais plantados no Brasil vem aumentando a participação nas exportações e representa grande importância na geração de empregos. Segundo o último relatório da FAO sobre florestas (Global Forest Resources Assessment) as florestas plantadas ocupam cerca de 264 milhões de hectares, representado $7 \%$ da superfície da área de florestas no mundo com uma demanda de novos plantios de 5,2 milhões de hectares por ano (FAO, 2010). No Brasil a área plantada é de cerca de 7 milhões de hectares (ABRAF, 2012). Por apresentar condições favoráveis para $o$ desenvolvimento de florestas plantadas, o Brasil apresenta-se como uma futura potencia no setor com ampla capacidade de expansão de áreas plantadas e produtividade.

Há um grande número de espécies com potencial madeireiro ainda pouco estudado (ZENID, 2000; IPEF, 2013) e essa grande diversidade de espécies promissoras necessitam de melhores pesquisas quanto à eficiência na produção de madeira para os diferentes setores florestais. Fatores como adaptação as diferentes tipos de clima e solo ainda são temas de estudos escassos e pouco aprofundados para a maioria das espécies florestais, principalmente para regiões onde a atividade florestal apresenta importância local como é o caso da região do Baixo Acaraú no Estado do Ceará. O elevado déficit hídrico, má distribuição de chuvas, solos rasos e com pouca capacidade de retenção de água, além de baixos teores de nutrientes e matéria orgânica, são alguns dos aspectos que necessitam ser pesquisados.

A redução da disponibilidade hídrica causa efeitos diretos na capacidade fotossintética das plantas, afetando as reações bioquímicas e o funcionamento do aparato fotossintético, e indiretamente pelo fechamento estomático (LAWLOR; CORNIC, 2002; SILVA et al., 2008; RODRIGUES et al., 2011; TONELLO; TEIXEIRA FILHO, 2012; CUNHA et al., 2013). A diminuição da abertura estomática é observada por muitos autores como sendo umas das respostas diretas ao estresse hídrico (LIBERATO et al., 2006; LIMA et al., 2010; WARREN et al., 2011; ALBUQUERQUE et al., 2013), como forma de reduzir aperda de água e a possibilidade de morte por dessecação (NOGUEIRA; SILVA, 2002; SILVA et al., 2009; CORDEIRO et al., 2009; SCALON et al., 2011). Por outro lado, a análise qualitativa e quantitativa da absorção e aproveitamento da energia luminosa pelo fotossistema II tem sido utilizada para investigar possíveis relações do estresse hídrico com a capacidade fotossintética e a redução da assimilação de $\mathrm{CO}_{2}$ (MAXWELL; JOHNSON, 2000; GONÇALVES et al., 2009; LAGE-PINTO et al., 2012; ESPOSTI, 2013).

O presente estudo teve como objetivo avaliar as trocas gasosas e a eficiência do fotossistema II em plantas adultas de seis espécies arbóreas cultivadas em condições de sequeiro e irrigadas, no Perímetro Irrigado do Baixo Acaraú, Ceará.

\section{MATERIAL E MÉTODOS}

O trabalho foi conduzido no período de setembro de 2012 a junho de 2013 em uma área experimental da Embrapa, localizado no perímetro irrigado do Baixo Acaraú, situada a 2,2 Km da margem direita da CE178, no município de Acaraú, Ceará, Brasil, com coordenadas de $3^{\circ} 27^{\prime} 06^{\prime}$ " de latitude Sul, $40^{\circ} 08^{\prime} 48^{\prime}$ " de longitude Oeste e altitude média de $60 \mathrm{~m}$. O clima da região segundo a classificação de Köppen é o Aw (Tropical Chuvoso), com precipitação média anual de $900 \mathrm{~mm}$, temperatura média anual $28,1^{\circ} \mathrm{C}$, insolação de $2.650 \mathrm{~h} \mathrm{ano}^{-1}$, umidade relativa média anual $70 \%$, velocidade média dos ventos $3,0 \mathrm{~m} \mathrm{~s}^{-1}$ e evaporação média anual $1.600 \mathrm{~mm}$. DNOCS (2013).

Os dados mensais de precipitação (mm), temperatura do ar $\left({ }^{\circ} \mathrm{C}\right)$, umidade relativa do ar $(\%)$ e velocidade do vento $\left(\mathrm{m} \mathrm{s}^{-1}\right)$, no período de setembro de 2012 a junho de 2013, foram, respectivamente: $0,0,28,3,60,5$ e 4,8 (setembro), 0,0, 28,4, 62,6 e 5,0 (outubro), 7,2, 28,1,65,9 e 4,2 (novembro), 8,4, 27,9, 70,8 e 4,0 (dezembro), 35,9, 28,1,70,5 e 3,6 (janeiro), 46,4,28,1, 72,3 e 3,6 (fevereiro), $79,7,27,9,73,9$ e 3,5 (março), 234,0, 26,8, 80,2 e 2,5 (abril), 166,0, 26,9, 78,3 e 2,9 (maio), 46,3, 26,6, 77, 1 e 3,0 (junho). Os dados foram obtidos de uma Estação Meteorológica Automática localizada no Perímetro Irrigado do Baixo Acaraú, Ceará, pertencente ao Instituto Nacional de Meteorologia (INMET), distante cerca de $3 \mathrm{~km}$ da área experimental.

O solo da área experimental foi classificado como Neossolo quartzarênico (EMBRAPA, 2013), e apresentava as seguintes características na camada de 0 a $50 \mathrm{~cm}$ : classe textural areia, umidade do solo a 0,03 MPA de $4,38 \%$, umidade a $1,5 \mathrm{MPa}$ de 2,95\%, $\mathrm{pH} 6,1, \mathrm{CE} 0,19$ $\mathrm{dS} \mathrm{m}{ }^{-1}$, matéria orgânica $9,0 \mathrm{~g} \mathrm{Kg}^{-1}, \mathrm{P} 19,9 \mathrm{mg} \mathrm{dm}^{-3}$, e $14,65,6,45,1,05,3,35$ e 5,4 mmolc dm ${ }^{-3} \mathrm{de} \mathrm{Ca}^{+2}, \mathrm{Mg}^{2+}$, $\mathrm{K}^{+}, \mathrm{Na}^{+} \mathrm{H}^{+}+\mathrm{Al}^{+3}$, respectivamente. 
As espécies utilizadas foram o Gonçalo Alves (Astronium fraxinifolium Schott); Guanandi (Calophyllum brasiliense Cambess.); Ipê-Amarelo (Handroanthus serratifolius (Vahl.); Ipê-Rosa (Handroanthus impetiginosa (Mart.) Matos.); Marupá (Simarouba amara Aubl.) e Mogno (Swietenia macrophylla King).

No primeiro ano toda a área foi irrigada e logo após esse período as parcelas foram divididas em duas subáreas (subparcelas), uma que foi irrigada continuamente (regime irrigado) e outra que a irrigação foi suspensa no final do primeiro ano de cultivo (regime não irrigado). Foi utilizado um sistema de irrigação por microaspersão, sendo aplicada uma lâmina diária de $2,7 \mathrm{~mm} \mathrm{dia}^{-1}$ em todas as plantas durante o primeiro ano, e de 5,0 $\mathrm{mm} \mathrm{dia}^{-1}$ nas plantas que permaneceram irrigadas a partir do segundo ano de cultivo.

Em outubro de 2010 as espécies foram plantadas e as avaliações foram iniciadas cerca de dois anos após as mudas serem levadas ao campo. Cada subparcela experimental tinha $6 \times 28 \mathrm{~m}$ constituídas por três linhas, composta de 15 plantas/linha, sendo a primeira e a terceira consideradas bordaduras, bem como as duas plantas dos extremos da linha central, totalizando o número de 13 plantas na área útil. O espaçamento utilizado foi de $3 \mathrm{~m}$ entre as linhas e $2 \mathrm{~m}$ entre plantas.

As análises das trocas gasosas foram realizadas em 22/11/2012 (estação seca), 07/02/2013 (data que antecedeu o período chuvoso) e 17/05/2013 (estação chuvosa). As trocas gasosas foram obtidas com o auxílio de um analisador de gás infravermelho (IRGA Modelo LI-6400XT, Licor, USA), sendo as leituras realizadas nos períodos da manhã (entre 8 e 11 horas) e da tarde (entre 12 e 15 horas), sob luz saturante com densidade de fluxo de fótons fotossinteticamente ativos de aproximadamente $1.200 \mu \mathrm{mol} \mathrm{m}{ }^{-1} \mathrm{~s}^{-1}$ e sob condições de temperatura e concentração de $\mathrm{CO}_{2}$ ambientes. As leituras foram realizadas em três plantas de cada tratamento, utilizando-se folhas completamente expandidas e em bom estado fitossanitário.

As medições da fluorescência da clorofila- $a$ foram realizadas em 22/11/2012 (estação seca), 07/02/2013 (data que antecedeu o período chuvoso) e 17/05/2013 (estação chuvosa) com o auxílio de um fluorômetro portátil (Plant Efûciency Analyser - MK2 - 9600, Hansatech, Norfolk, UK) sendo as leituras realizadas entre as 08:00 e 15:00 horas, em folhas completamente expandidas em temperatura ambiente, aclimatadas ao escuro (com clipes foliares) por $30 \mathrm{~min}$.

A umidade do solo foi determinada pelo método gravimétrico, conforme Donagema et al. (2011), nas mesmas datas de avaliações de trocas gasosas e da fluorescência. Em cada coleta foram abertas trincheiras de $60 \mathrm{~cm}$ na área da linha central de cada subparcela, sendo as amostras coletadas em três profundidades $(0-20 \mathrm{~cm} ; 20-40 \mathrm{~cm} ; 40-60 \mathrm{~cm})$, com três repetições em cada profundidade.

O delineamento experimental adotado foi o de medidas repetidas no tempo, num esquema de parcelas subsubdividida $(6 \times 2 \times 3)$, sendo a parcela principal composta por seis espécies, a subparcela por dois regimes hídricos (irrigado e sequeiro) e a subsubparcela pelas épocas de avaliação. Foram realizadas múltiplas observações da mesma planta nesses diferentes tempos, considerando cada planta como uma repetição.

Os dados obtidos foram avaliados e submetidos à análise de variância com observações repetidas no tempo. Para os efeitos significativos de fatores isolados e interações foi aplicado o Tukey de comparação de médias a 5\% de probabilidade, utilizando o software estatístico SISVAR (FERREIRA, 2008).

\section{RESULTADOS}

\subsection{Umidade do solo}

Os perfis de umidade do solo nos dois regimes hídricos (irrigado e sequeiro) e nas diferentes épocas de avaliação estão apresentados na Figura 1. Na camada superficial verificaram-se valores de umidade de 1,3, 1,2 e 4,4\% nos solos cultivados sem uso da irrigação nos meses de novembro, fevereiro e maio, respectivamente, com valores levemente maiores nas camadas mais profundas. Esses valores para as parcelas continuamente irrigadas foram 7,7, 6,7 e 5,0\%, respectivamente para os meses de novembro, fevereiro e maio.

\section{2. Condutância Estomática}

As plantas de mogno, guanandi e ipê-amarelo em condições de sequeiro apresentaram menores valores de condutância estomática significativamente no turno da manhã, em relação às plantas irrigadas no mesmo horário (Figura 2A). Essas espécies apresentaram

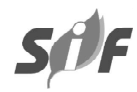

Revista Árvore, Viçosa-MG, v.39, n.5, p.973-983, 2015 


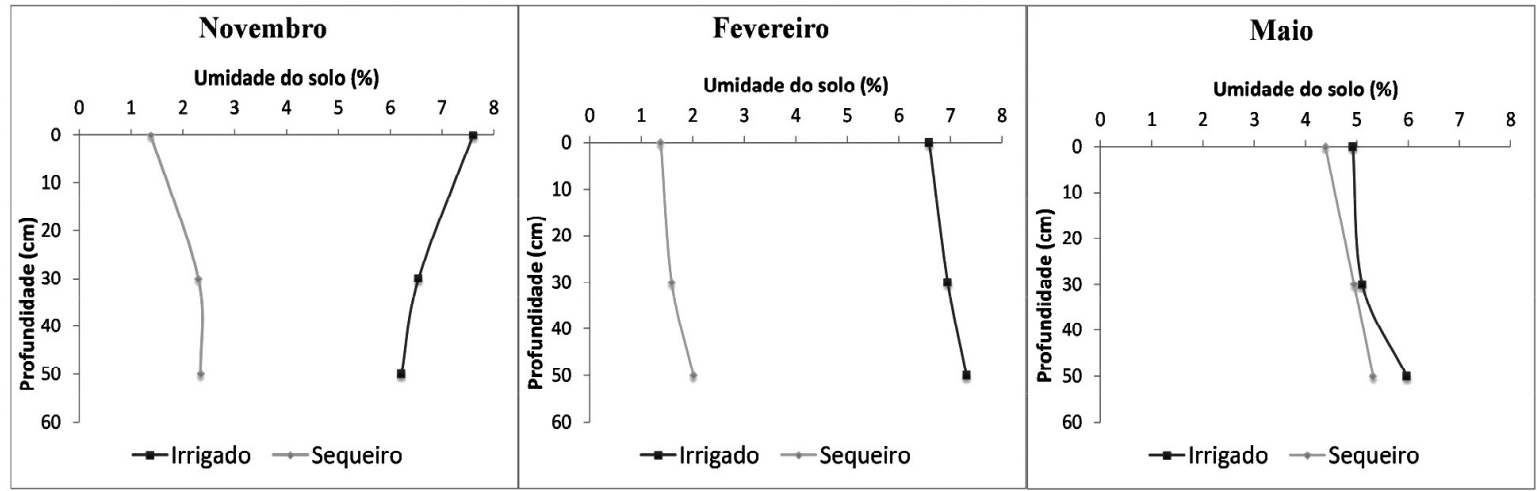

Figura 1 - Perfil de umidade do solo nas áreas irrigadas e de sequeiro, nas épocas de avaliação.

Figure 1 -Soil moisture profile in irrigated and non-irrigated conditions in the evaluation times.

(A)

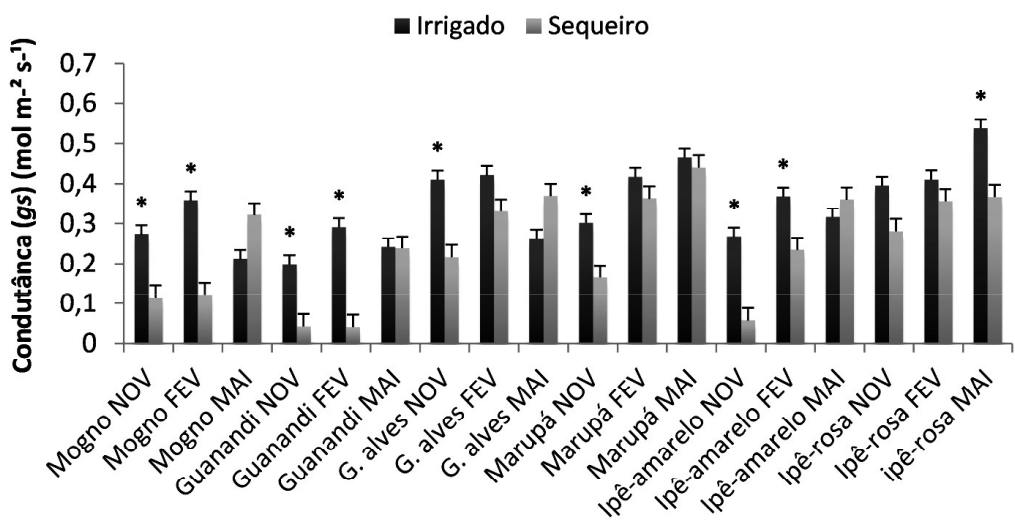

(B)

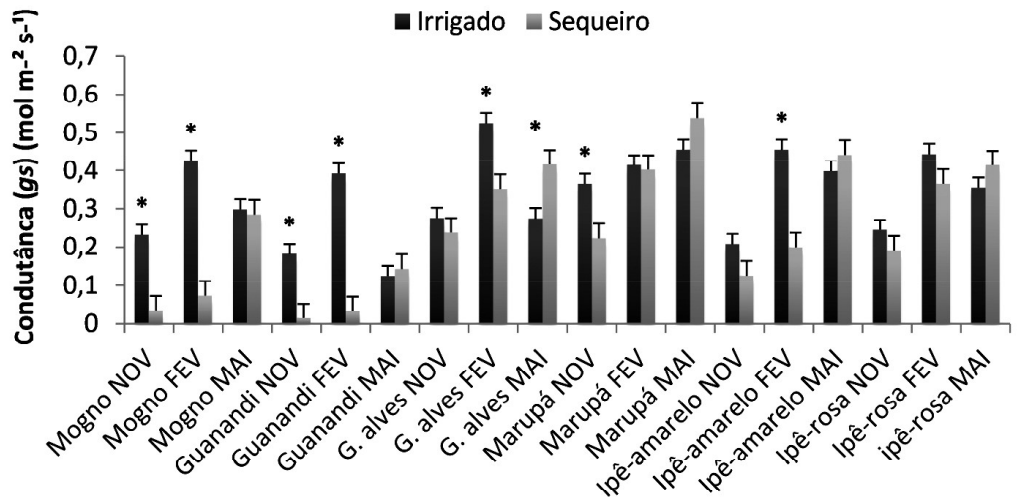

Figura 2 - Condutância estomática (gs) em seis espécies arbóreas submetidas a condições irrigadas e de sequeiro nos meses de novembro, fevereiro e maio, no turno da manhã (A) e da tarde (B). * Significativo pelo teste de Tukey a $5 \%$. As barras de erro representam o erro-padrão da média $(n=4)$.

Figure 2 - Stomatal conductance (gs) of six tree species under irrigated and non-irrigated conditions in the months of November, February and May in the morning (A) and afternoon (B). * Significant by Tukey Test at 5\% probability. Error bars represent standard error of the mean $(n=4)$.

Revista Árvore, Viçosa-MG, v.39, n.5, p.973-983, 2015 
recuperação somente na época chuvosa (maio). Por outro lado, as plantas não irrigadas de gonçalo-alves e marupá apresentaram a $g_{s}$ negativamente afetada somente no período mais seco (novembro) e recuperação nos meses de fevereiro e maio. O ipê-rosa somente apresentou diferença significativa entre os regimes hídricos no mês de maio, causada por um aumento expressivo da $g_{s}$ nas plantas irrigadas.

As leituras de condutância estomática no turno da tarde confirmaram os maiores efeitos do estresse hídrico sobre as plantas de mogno e guanandi (Figura 2B) com reduções significativas da $g_{s}$ nos meses mais secos e recuperação apenas na época chuvosa. $\mathrm{O}$ gonçalo-alves, marupá e ipê-amarelo apresentaram aumento considerável na $g_{s}$ no mês de fevereiro em relação a novembro, e posterior recuperação em maio. Nas plantas de ipê-rosa a $g_{s}$ não foi influenciada significativamente pelo regime hídrico nas épocas mais secas (novembro e fevereiro).

\subsection{Fotossíntese}

Observa-se na Figura 3 a variação da taxa da fotossíntese em plantas irrigadas e de sequeiro em função das épocas de avaliação nos períodos da manhã e da tarde. Verificou-se que no período da manhã (Figura 3A) com exceção do ipê-rosa, todas as espécies em condições de sequeiro tiveram a assimilação de $\mathrm{CO}_{2}$ afetadas significativamente no mês de novembro. No mês que antecedeu o período chuvoso, fevereiro, as espécies mogno, guanandi e ipê-amarelo tiveram a $A$ afetadas negativamente em condições de déficit hídrico, com as demais espécies apresentando recuperação em relação à análise anterior. Na medição realizada no período chuvoso (maio) observou-se uma recuperação das plantas de sequeiro em resposta a disponibilidade de água no solo. Essa recuperação foi mais expressiva no mogno e no guanandi com aumento de $151,25 \%$ e 2043,09\%, respectivamente, em comparação com o período mais seco.

No turno da tarde houve uma tendência de queda nas taxas fotossintéticas das plantas cultivadas sob sequeiro (Figura 3B), principalmente nos meses mais secos (novembro e fevereiro), apresentando diferença significativa nessas duas épocas. $\mathrm{Na}$ época chuvosa (maio) ocorreu aumento das taxas de $A$ nas plantas de sequeiro, expressando uma recuperação, em função das melhores condições de umidade do solo.

\subsection{Transpiração}

As medições de transpiração realizadas no turno da manhã (Figura 4A) mostraram reduções significativas no mogno e guanandi nas condições de regime de sequeiro nas épocas de seca (novembro e fevereiro), com recuperação apenas no mês de maio. O gonçalo-alves e o ipê-amarelo tiveram a $E$ reduzidas significativamente apenas no mês mais seco (novembro), enquanto que o marupá e o ipêrosa não alteraram de forma significativa as taxas transpiratórias em função do regime hídrico nas três épocas.

No turno da tarde (Figura 4B) as taxas transpiratórias do mogno, guanandi e ipê-amarelo mantiveram-se reduzidas nos dois meses mais secos (novembro e fevereiro). O marupá teve as taxas de $E$ reduzidas apenas no mês mais seco (novembro), com recuperação em fevereiro. O ipê-rosa e gonçalo-alves não alteraram a $E$ nesse turno em função do regime hídrico nas três épocas de avaliação.

\subsection{Fluorescência da clorofila (Eficiência quântica do fotossistema II)}

A relação $F v / F m$ foi reduzida de forma significativa no guanandi em condições de sequeiro nos meses de novembro e fevereiro (Figura 5). No mogno essa redução foi somente observada no mês de novembro e no ipêamarelo no mês de fevereiro. As demais espécies não alteraram de forma significativa a relação $F v / F m$ em função do regime hídrico nas três épocas de avaliação.

\section{DISCUSSÃO}

Os valores de umidade do solo refletiram o manejo de irrigação empregado e a ocorrência de chuvas durante o período de estudo (Figura 1), bem como o tipo de solo da área experimental. É importante ressaltar que a umidade do solo nas áreas não irrigadas durante os períodos de seca (entre 1,2 e 2,3\%) foram inferiores ao valor medido em laboratório na tensão correspondente ao ponto de murcha permanente (-1,5 $\mathrm{MPa})$, sendo este último de $3 \%$.

As variações na condutância estomática refletiram as variações na umidade do solo, decorrentes do manejo da irrigação e da ocorrência ou não de chuvas (Figura 2). As reduções da $g_{s}$ demonstram que a maioria das espécies estudadas promove o fechamento estomático para diminuir a perda de água quando expostas a condições de baixa disponibilidade hídrica. No entanto, os efeitos

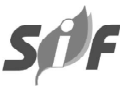

Revista Árvore, Viçosa-MG, v.39, n.5, p.973-983, 2015 
(A)

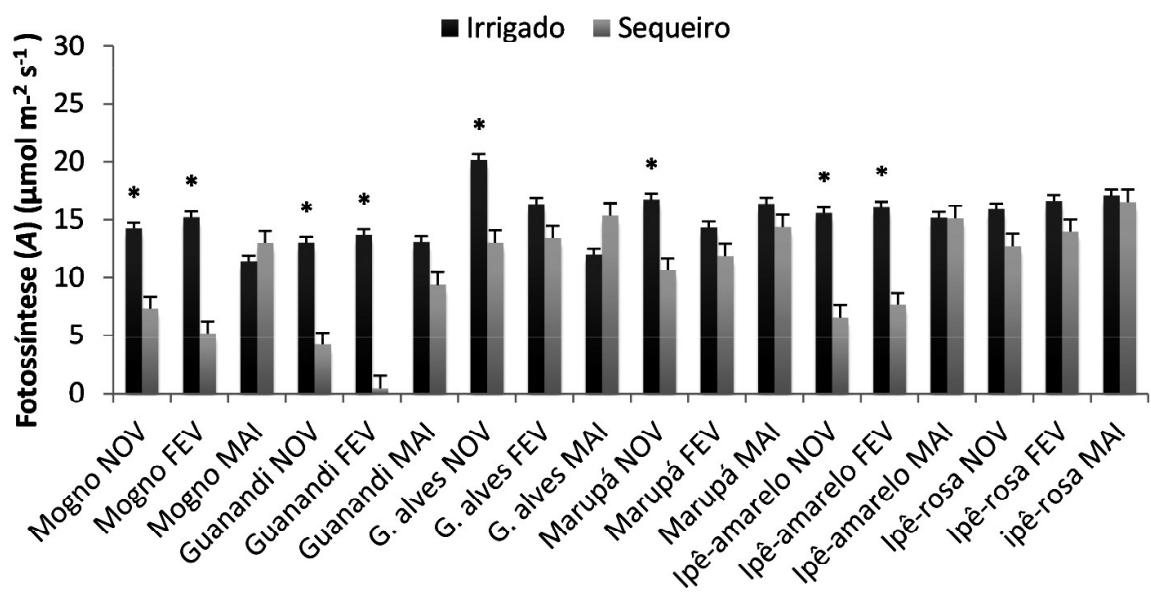

(B)

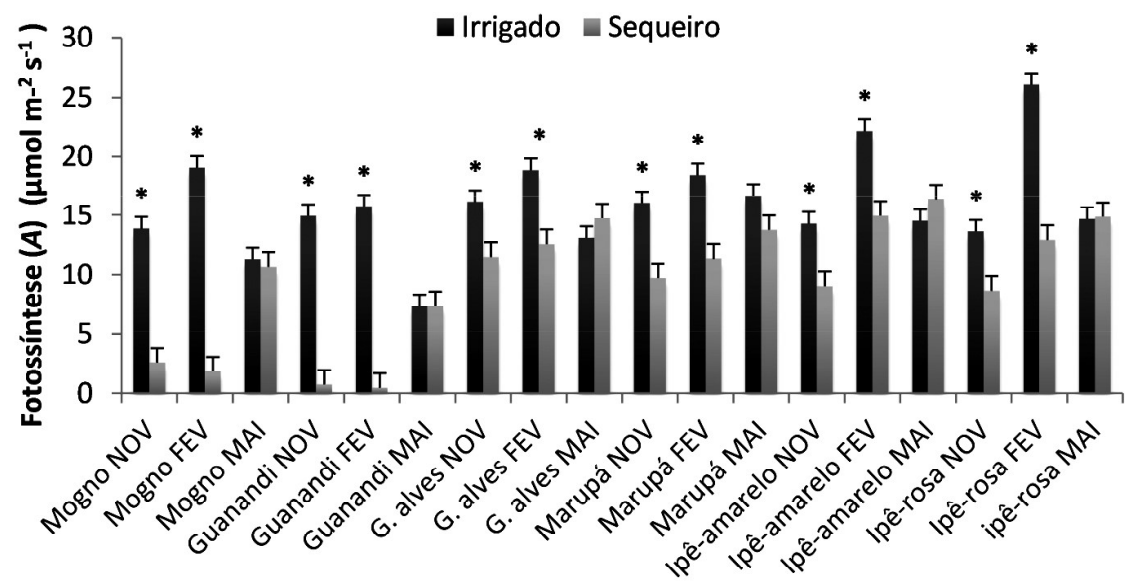

Figura 3 - Taxa fotossintética (A) em seis espécies arbóreas submetidas a condições irrigadas e de sequeiro nos meses de novembro, fevereiro e maio, no turno da manhã (A) e da tarde (B). ${ }^{*}$ Significativo pelo teste de Tukey a $5 \%$. As barras de erro representam o erro-padrão da média $(\mathrm{n}=4)$.

Figure 3 - Photosynthetic rate (A) of six tree species under irrigated and non-irrigated conditions in the months of November, February and May in the morning (A) and afternoon (B). * Significant by Tukey Test at 5\% probability. Error bars represent standard error of the mean $(n=4)$.

da seca no mogno e guanandi foram bem mais intensos diante da severidade do estresse, em comparação com as outras espécies, sendo que as poucas chuvas ocorridas no mês de janeiro não foram suficientes para reverter os efeitos do déficit hídrico nessas espécies. Por outro lado, o gonçalo-alves, ipê-rosa e marupá sofreram menor impacto da deficiência de água no solo sobre a abertura estomática, sugerindo a possibilidade dessas espécies apresentarem outros mecanismos de convivência com a seca.
Sob condições de estresse, especialmente hídrico e salino, o fechamento estomático pode ser visto como uma resposta positiva da planta para a manutenção de água (TAIZ; ZEIGER, 2013). Esses resultados são semelhantes aos encontrados por Tonello e Teixeira Filho (2012) que constataram a diminuição dos valores de condutância estomática em Pterogyne nitens, Aspidosperma polyneuron e Myroxylum peruiferum quando submetidas a diferentes disponibilidades de água no solo, e aos observados por Cunha et al. (2013) 
(A)

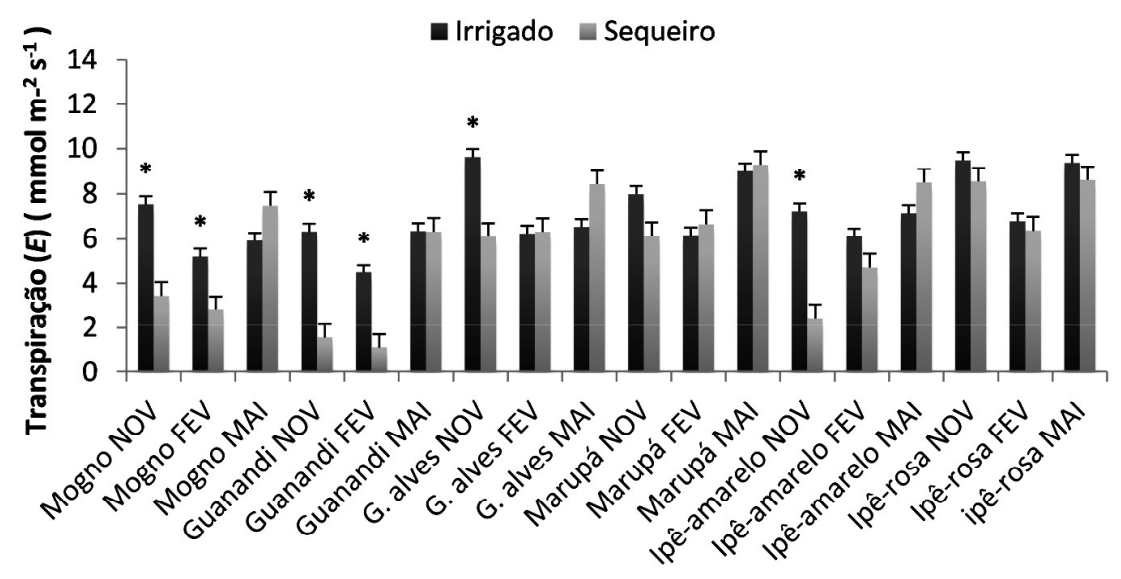

(B)

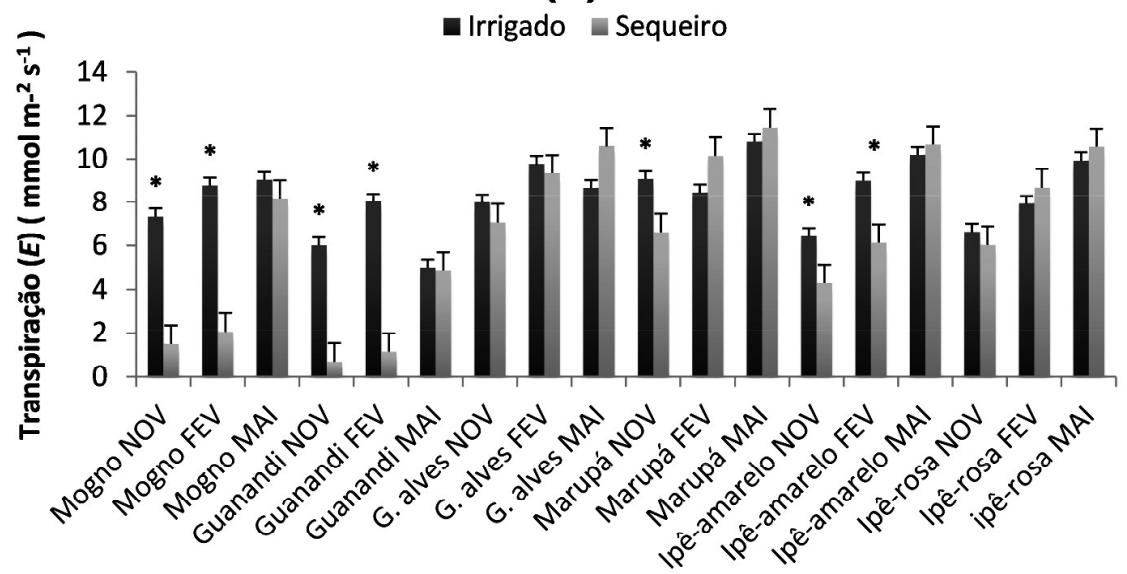

Figura 4 - Taxa de transpiração $(E)$ em seis espécies arbóreas submetidas a condições irrigadas e de sequeiro nos meses de novembro, fevereiro e maio, no turno da manhã (A) e da tarde (B). * Significativo pelo teste de Tukey a $5 \%$. As barras de erro representam o erro-padrão da média $(\mathrm{n}=4)$.

Figure 4-Transpiration rate (E) in six tree species under irrigated and non-irrigated conditions in the months of November, February and May in the morning (A) and afternoon (B). * Significant by Tukey Test at 5\% probability. Error bars represent standard error of the mean $(n=4)$.

que constataram em plantas de Swietenia macrophyllae Khaya ivorensis reduções na faixa de $75 \%$ à $90 \%$ na $g_{s}$ nos períodos mais secos. Silva et al. (2008) em trabalho com Schinus terebinthifolius observaram redução da $g_{s}$ nessa planta quando submetida a diferentes regimes hídricos. Rodrigues et al. (2011) ao investigarem o efeito da sazonalidade climática na condutância estomática em Jatropha curcas nas condições do semiárido, constataram decréscimo da $g_{s}$ nas épocas de menor precipitação pluviométrica, e observaram que além da disponibilidade de água no solo outros fatores como temperatura do ar, radiação fotossinteticamente ativa e déficit de pressão de vapor do ar influenciaram nas respostas fisiológicas nessa espécie. Já em regiões em que a sazonalidade das épocas de precipitação pouco altera a umidade do solo, observa-se que a $g_{s}$ sofre pouca alteração, como relata Mendes e Marenco (2010) em trabalho com dez espécies nativas na região da Amazônia Central, embora as taxas de fotossíntese máxima tenham sido menores no período seco. Segundo

Revista Árvore, Viçosa-MG, v.39, n.5, p.973-983, 2015 


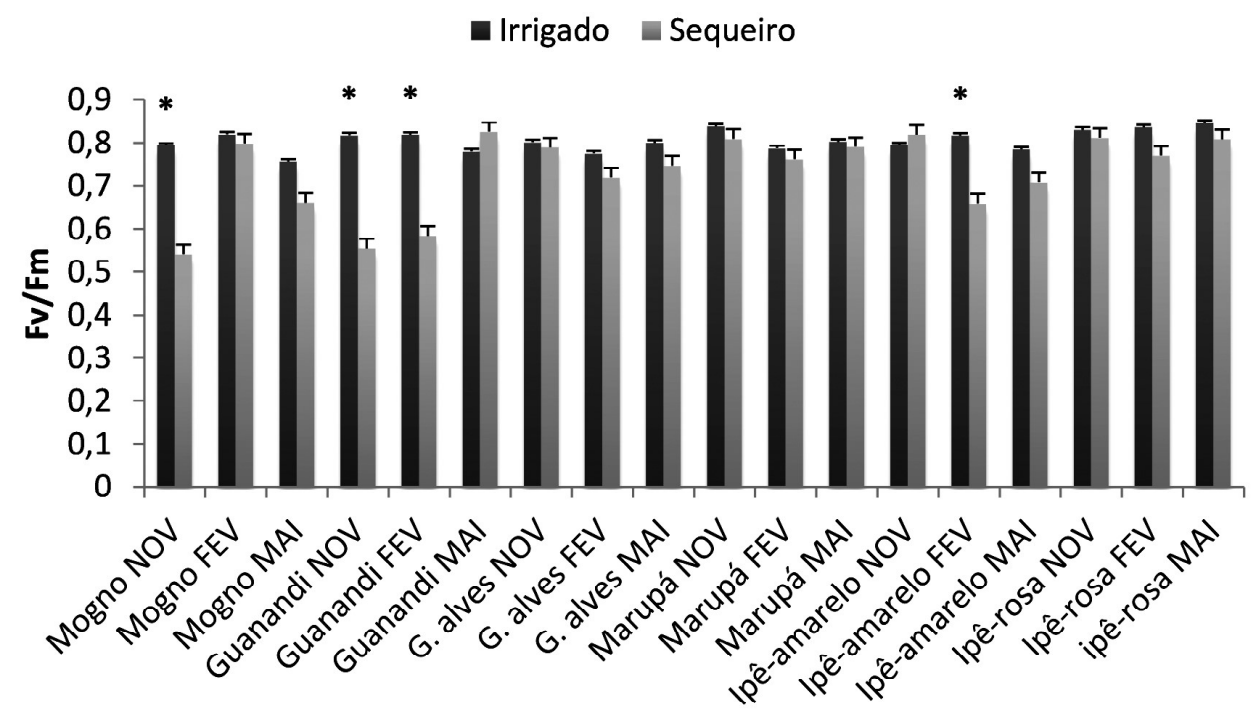

Figura 5 - Eficiência quântica do fotossistema II $(F v / F m)$ em seis espécies arbóreas submetidas a condições irrigadas e de sequeiro, nos meses de novembro, fevereiro e maio.* Significativo pelo teste de Tukey a 5\%. As barras de erro representam o erro-padrão da média $(\mathrm{n}=4)$.

Figure 5 - Quantum efficiency of photosystem II (Fv/Fm) in six tree species under irrigated and non-irrigated conditions in the months of November, February and May. * Significant by Tukey Test at $5 \%$ probability. Error bars represent standard error of the mean $(n=4)$.

Larcher (2006) o grau de abertura estomática se ajusta continuamente às oscilações dos fatores ambientais.

As plantas de mogno, guanandi e ipê-amarelo mostraram-se mais sensíveis às mudanças de umidade do solo, com taxas de $A$ afetadas nos dois turnos (Figura 3). As taxas de fotossíntese das demais espécies foram afetadas somente no período mais crítico do dia. $\mathrm{Na}$ época chuvosa, no mês de maio, a recuperação das plantas de sequeiro foi evidenciada em todas as espécies, com taxas de $A$ significativamente iguais para as duas condições de regime hídrico. A respostas dessas espécies são semelhantes às obtidas em plantas de Khaya ivorensis (ALBUQUERQUE et al., 2013), Carapa guianensis (GONÇALVES et al., 2009), Minquartia guianensis (LIBERATO et al., 2006), eucalyptus e acácia spp. (WARREN et al., 2011), Swietenia macrophylla (CORDEIRO et al., 2009) e Anacardium occidentale L. em algumas épocas do ano (LIMA et al., 2010). A redução de $A$, em plantas submetidas ao déficit hídrico, ocorrem por diversas razões, tais como limitação estomática ao fluxo de $\mathrm{CO}_{2}$, danos ao aparato fotoquímico da fotossíntese, redução na síntese de ATP e diminuição da atividade da Rubisco (Ribulose-1,5-bifosfato carboxilase oxigenase) ou em sua taxa de regeneração
(FLEXAS; MEDRANO, 2002). Segundo Larcher (2006) a capacidade fotossintética altera-se sazonalmente em função das adaptações às condições ambientais. Mendes et al. (2013) em trabalho com Cordia oncocalyx caracteriza bem essa alteração nas respostas fisiológicas durante as estações chuvosa e seca no semiárido brasileiro.

No presente estudo verifica-se que as reduções da taxa fotossintética (Figura 3 ) podem ser explicadas, em grande parte, pelo fechamento estomático (Figura 2) provocado pelo estresse hídrico. É importante destacar, no entanto, que as reduções nas taxas de fotossíntese (Figura 3) nem sempre foram acompanhadas de reduções na concentração interna de $\mathrm{CO}_{2}$ (dados não mostrados), fato que evidenciaria a existência de limitações estomáticas. Para as espécies mogno e ipê-rosa, por exemplo, verificou-se redução na concentração interna de $\mathrm{CO}_{2}$ apenas no mês de novembro, enquanto para o guanandi verificou-se redução nos meses de novembro (manhã e tarde) e fevereiro (tarde). Para as demais espécies não se observou influência do regime hídrico sobre a concentração interna de $\mathrm{CO}_{2}$. Portanto, esses dados indicam que alguma limitação não estomática, pode também ter contribuído para a redução nas taxas de fotossíntese (FLEXAS; MEDRANO, 2002). 
As variações das taxas transpiratórias (Figura 4) seguiram a mesma tendência da condutância estomática (Figura 2), o que mostra que as plantas diminuem as perdas de água por transpiração por meio do fechamento estomático de acordo com as condições de disponibilidade hídrica. Quanto à resposta das diferentes espécies, o mogno e guanandi tiveram a $E$ mais afetadas nas épocas mais secas, nos dois turnos, seguida de recuperação na época chuvosa. O ipê-amarelo, gonçaloalves e marupá foram afetadas somente no mês mais seco e no turno da tarde, onde as condições ambientais são mais intensas. O ipê-rosa foi a espécies que apresentou maior controle das taxas transpiratórias em condições de baixa disponibilidade de água no solo. Esses resultados corroboram com Cordeiro et al. (2009) que verificaram menores taxas de transpiração em plantas de Swietenia macrophylla quando submetidas a deficiência hídrica concluindo que essa espécie é eficiente no controle das taxas transpiratórias. Esse comportamento também é semelhante ao encontrado por Scalon et al. (2011) em trabalho com Guazuma ulmifolia, onde as taxas de transpiração foram menores quando submetidas a menor fornecimento de água. Nogueira e Silva (2002) verificaram esse mesmo efeito em Schinopsis brasiliensis após a suspensão da irrigação. Em contrapartida, Tatagiba et al. (2008) em trabalho com clones de eucalipto em ambientes com diferentes disponibilidades de água no solo, verificaram que não houve diferença significativa na transpiração.

As respostas da fluorescência da clorofila foram mais expressivas nas espécies que tiveram maior grau de severidade do estresse hídrico: guanandi, mogno e ipê-amarelo (Figura 5). Essas espécies tiveram a eficiência fotoquímica afetada negativamente pela condição de déficit hídrico, com valores da relação $F v / F m$ de $0,555,0,541,0,619$ nas planta sob estresse hídrico de guanandi, mogno e ipê-amarelo. Esses valores estão bem abaixo do limite crítico de 0,75 para a relação Fv/Fm (MAXWELL; JOHNSON, 2000; TAIZ; ZEIGER, $2013)$. Esse resultado indica que pode ter ocorrido danos irreversíveis no aparato fotossintético dessas espécies em tal condição e pode justificar, também, a baixa capacidade de recuperação das taxas de fotossíntese dessas espécies após as primeiras chuvas. A recuperação dessas espécies durante a época das chuvas deve-se, provavelmente, à produção de novas folhas.
Alterações na $F v / F m$ em plantas submetidas a condições de estresse hídrico é relatada por vários autores, indicando que a redução na disponibilidade de água potencializa os processos fotoinibitórios (LAGE-PINTO et al., 2012). Em trabalho com espécies arbóreas da Caatinga nas épocas seca e chuvosa, Trovão et al. (2007) verificaram que das onze espécies sete não alteram a $F v / F m$ em relação aos períodos e as outras quatro apresentaram reduções mínimas e atribuem às características evolutivas dessas espécies. Esposti (2013) observou redução da $F v /$ Fm em Handroanthus chrysotrichus 15 dias após o início da restrição hídrica, já em Cariniana estrellensis esse parâmetro não foi alterado sob as mesmas condições. Gonçalves et al. (2009) observaram uma redução de $23 \%$ na $F v / F m$, após 14 dias de supressão de irrigação em plantas jovens de Carapa guianensis e atribuem esse fato da redução da atividade fotoquímica em decorrência da diminuição da $g_{s}$ ocasionada pelo estresse hídrico e relatam que a fotoinibição ocorre em condições de seca mais severa. Neste trabalho essa situação foi observada apenas para o mogno, guanandi e ipê-amarelo sob estresse hídrico severo.

\section{CONCLUSÕES}

1. As espécies mogno, guanandi e ipê-amarelo mostraram-se mais sensíveis ao déficit hídrico em comparação com as outras espécies, evidenciado pelas maiores reduções nas trocas gasosas e na eficiência fotoquímica do fotossistema II.

2. O ipê-rosa, marupá e gonçalo-alves mostraramse mais adaptadas às condições de baixa disponibilidade hídrica do solo.

\section{AGRADECIMENTOS}

Os autores agradecem à CAPES pela concessão da bolsa de estudo, à Embrapa Agroindústria Tropical, Agência de Desenvolvimento do Estado do Ceará (ADECE), Banco do Nordeste do Brasil (BNB) e Universidade Federal do Ceará pelo suporte financeiro, bem como aos demais parceiros do projeto: Embrapa Floresta, Departamento Nacional de Obras Contra as Secas (DNOCS), Sindicato das Indústrias de Móveis do Ceará (Sindmóveis), Instituto de Desenvolvimento Industrial do Ceará (INDI) e Fabricantes Associados de Marco, Ceará (FAMA).

\section{silf}

Revista Árvore, Viçosa-MG, v.39, n.5, p.973-983, 2015 


\section{REFERÊNCIAS}

ASSOCIAÇÃO BRASILEIRA DE PRODUTORES DE FLORESTAS PLANTADAS - ABRAF.

Anuário estatístico da ABRAF 2012 ano base 2011. Brasília: 2012. 150p.

ALBUQUERQUE, M. P. F.; MORAES, F. K. C.; SANTOS, R. I. N.; CASTRO, G. L. S.; RAMOS, E. M. L. S.; PINHEIRO, H. A. Ecofisiologia de plantas jovens de mogno-africano submetidas a déficit hídrico e reidratação. Pesquisa Agropecuária. Brasileira, v.48, n.1, p.9-16, 2013.

CORDEIRO, Y. E. M.; PINHEIRO, H. A.; SANTOS FILHO, B. G.; CORRÊA, S. S.; SILVA, J. R. R.; DIAS-FILHO, M. B. Physiological and morphological responses of young mahogany (Swietenia macrophylla King) plants to drought. Forest Ecology and Management, v.258, p.1449-1455, 2009.

CUNHA, R. L. M.; FILHO, B. G. S.; COSTA, R. C. L.; VIÉGAS, I. J. M. Physiological assessment in young Brazilian and African mahogany plants during the dry and rainy seasons in northeastern Para state, Brazil. Revista Ciências Agrárias, v.56, n.3, p.255-260, 2013.

DNOCS - DEPARTAMENTO NACIONAL DE OBRAS CONTRAAS SECAS. Grupos de Coordenação Executiva das Operações Agrícolas (GOA). Situação em 30/04/1991. DNOCS -

Perímetro irrigado Baixo-Acaraú. Fortaleza: 2012. Disponível em: http://www.dnocs.gov.br/ dnocs/ doc/canais/perimetros_irrigados/ce/

baixo_acarau.html. Acesso em 8 de abril de 2013 .

DONAGEMA, G. K.; CAMPOS, D. V. B.; CALDERANO, S. B.; TEIXEIRA, W. G.; VIANA, J. H. M. (Org.). Manual de métodos de análise de solos. 2.ed. rev. Rio de Janeiro: Embrapa Solos, 2011.230p

EMPRESA BRASILEIRA DE PESQUISA AGROPECUÁRIA - EMBRAPA. Sistema Brasileiro de Classificação de solos. $3^{a}$. ed. Brasília: Embrapa Produção de Informação, Rio de Janeiro: 2013: 353p.

ESPOSTI, M. S. O. D. Estresse hídrico em duas espécies arbóreas de diferentes

Revista Árvore, Viçosa-MG, v.39, n.5, p.973-983, 2015 estágios sucessionais. 2013. 46 f. Dissertação (Mestrado em Ecologia e Recursos Naturais) Universidade Estadual Do Norte Fluminense, Campos dos Goytacazes - RJ, 2013.

FERREIRA, D. F. SISVAR: um programa para análises e ensino de estatística. Revista Symposium, v.6, n.1, p.36-41, 2008.

FLEXAS, J.; MEDRANO, H. Drought-inhibition of photosynthesis in C3 plants: stomatal and nonstomatal limitations revisited. Annals of Botany, v.89, n.2, p.183-189, 2002.

FOOD AND AGRICULTURE ORGANIZATION OF THE UNITED NATIONS - FAO. Global forest resources assessment 2010. Roma: 2010. $340 \mathrm{p}$.

GONÇALVES, J.F.C.; SILVA, C.E.M.; GUIMARÃES, D.G. Fotossíntese e potencial hídrico foliar de plantas jovens de andiroba submetidas à deficiência hídrica e à reidratação. Pesquisa Agropecuária Brasileira, v.44, n.1, p.8-14, 2009.

INSTITUTO DE PESQUISAS E ESTUDOS FLORESTAIS - IPEF. Elaboração de lista de espécies arbóreas nativas para silvicultura e modelos de uso múltiplo. Disponível em: $<$ http://www.ipef.br/pcsn/ documentos/especies_nativas_silvicultura.pdf $>$. Acesso em: 16 jul. de 2013 .

LAGE-PINTO, F.; BERNINI, E.; OLIVEIRA, J, G.; VITÓRIA, A, P. Photosynthetic analyses of two native Atlantic Forest species in regenerative understory of eucalyptus plantation. Brazilian Journal Plant Physiology, v.24, n.2, p.95106, 2012.

LARCHER, W. Ecofisiologia vegetal. São Carlos: RIMA, 2006. 531p.

LAWLOR, D.W.; CORNIC, G. Photosynthetic carbon assimilation and associated metabolism in relation to water deficits in higher plants. Plant, Cell and Environment, v.25, n.2, p.275-279, 2002.

LIBERATO, M. A. R.; GONÇALVES.; J. F. C.; CHEVREUIL, L. R.; NINA JUNIOR, A. R. N.; 
FERNANDES, A. V.; SANTOS JUNIOR, U. M. S. Leaf water potential, gas Exchange and chlorophyll a fluorescence in acariquara seedlings (Minquartia guianensis Aubl.) under water stress and recovery. Brazilian Journal Plant Physiology, v. 18, n.2, p.315-323, 2006.

LIMA, M. A.; BEZERRA, M. A.; GOMES FILHO, E.; PINTO, C. M.; FILHO, J. E. Trocas gasosas em folhas de sol e sombreadas de cajueiro anão em diferentes regimes hídricos. Revista Ciência Agronômica, v.41, n.4, p.654-663, 2010.

MAXWELL C.; JOHNSON, G.M. Chlorophyll fluorescence - a practical guide. Journal of Experimental Botany, v. 51, n.354, p.659-668, 2000.

MENDES, K.R.; MARENCO, R.A. Leaf traits and gas exchange in saplings of native tree species in the Central Amazon. Scientiae Agricola, v.67, n.6, p.624-632, 2010.

MENDES, M. M. S.; LACERDA, C. F.; FERNANDES, F. E. P.; CAVALCANTE, A. C. R.; OLIVEIRA, T. S. Ecophysiology of deciduous plants grown at different densities in the semiarid region of Brazil. Theoretical and Experimental Plant Physiology, v.25, n.2, p.97-108, 2013.

NOGUEIRA, R.J.M.C.; SILVA, E.C.

Comportamento estomático em plantas jovens de Schinopsis brasiliensis Engl. cultivadas sob estresse hídrico. Iheringia: Série Botânica, v.57, n.1, p.31-38, 2002.

RODRIGUES, B. M.; ARCOVERDE, G. B.; ANTONINO, A. C. D.; SANTOS, M. G. Water relations in physic nut according to climatic seasonality, in semiarid conditions. Pesquisa Agropecuária Brasileira, v.46, n.9, p.1112$1115,2011$.

SCALON, S. P. Q.; MUSSURY, R. M.; EUZÈBIO, V. L. M.; KODAMA, F. M.; KISSMANN, C. Estresse hídrico no metabolismo e crescimento inicial de mudas de Mutambo (Guazuma ulmifolia Lam.).Ciência Florestal, v.21, n.4, p.655-662, 2011.

SILVA, E. C.; NOGUEIRA, R. J.; VALE, F. H.; ARAÚJO, F. P. D.; PIMENTA, M. A. Stomatal changes induced by intermittent drought in four umbu tree genotypes. Brazilian Journal of Plant Physiology, v.21, n.1, p.33-42, 2009.

SILVA, M. A. V.; NOGUEIRA, R. J. M. C.; OLIVEIRA, A. F. M.; SANTOS, V. F. Resposta estomática e produção de matéria seca em plantas jovens de aroeira submetidas a diferentes regimes hídricos. Revista Árvore, Viçosa, v.32, n.2, p.335-344, 2008.

TAIZ, L.; ZEIGER, E. Fisiologia vegetal. 5. ed. Porto Alegre: Artmed, 2013.918p.

TATAGIBA, S.D.; PEZZOPANE, J.E.M.; REIS, E.F. Relações hídricas e trocas gasosas na seleção precoce de clones de eucalipto para ambientes com diferenciada disponibilidade de água no solo. Floresta, v.38, n.2, p.387-400, 2008.

TONELLO, K.C.; TEIXEIRA FILHO, J.

Ecofisiologia de três espécies arbóreas nativas da mata atlântica do Brasil em diferentes regimes de água. Irriga, v. 17, n.1, p.58-101, 2012.

TROVÃO, D. M. B. M.; FERNANDES, P. D.; ANDRADE L. A.; NETO J. D. Variações sazonais de aspectos fisiológicos de espécies da Caatinga. Revista Brasileira de Engenharia Agrícola e Ambiental, v.11, n.3, p.307-311, 2007.

WARREN, C.R.; ARANDA, I.; CANO, F.J. Responses to water stress of gas exchange and metabolites in Eucalyptus and Acacia spp. Plant, Cell and Environment, v.34, p.1609-1629, 2011.

ZENID, G.J. Madeiras para móveis e construção civil. São Paulo: Secretaria da Ciência, Tecnologia e Desenvolvimento Econômico do Estado de São Paulo, 2000. CDROM. (IPT. Publicação, 2779). 